\title{
Testosterone in COVID-19: Friend or Foe?
}

\author{
Peter J. Niemann ${ }^{1} \cdot$ Heidi V. Goldstein $\mathbb{1}^{2}$
}

Received: 4 January 2021 / Accepted: 9 January 2021 / Published online: 25 January 2021

This is a U.S. government work and not under copyright protection in the U.S.; foreign copyright protection may apply 2021

Coronavirus disease 2019 (COVID-19) as an ongoing disruptive pandemic poses significant challenges for the clinician. The pathogen responsible for COVID-19 is severe acute respiratory syndrome coronavirus-2 (SARS-CoV2). Although it is primarily a viral infection that affects the lower respiratory tract and lungs, it can target essentially all major organ systems. Endocrinological considerations surrounding testosterone seem particularly in need of discussion and to date present a management challenge, partly due to lack of high-quality evidence and resulting controversial interpretations.

It has been established that male mortality from COVID19 is higher than that of women, even when controlling for risk factors found more commonly in men such as hypertension, smoking, or cardiovascular disease. This has led scientists to postulate that testosterone plays a role in disease severity: SARS-CoV2 spike proteins are primed by transmembrane protease serine 2 , which itself is upregulated by testosterone. Furthermore, the spike proteins of SARS$\mathrm{CoV} 2$ then bind to angiotensin-converting enzyme 2 (ACE2) receptors to enter host cells, and ACE2 receptors are also regulated by testosterone [1].

In this context, there is conflicting data on the role of testosterone, its measurement, supplementation, and possible augmentation in COVID-19. While there has been some evidence to suggest a possible positive effect of androgendeprivation therapy (ADT) in prostate cancer patients infected by SARS-CoV2, this has recently been called into question [2]. Conversely, there is mounting evidence that low testosterone levels might actually worsen overall outcome-hypogonadism appears to be a risk factor for a more

Heidi V. Goldstein

hgoldstein@anest.ufl.edu

1 Excellence in Holistic Medicine, LLC, Sioux Falls, SD, USA

2 University of Florida, Gainesville, FL, USA severe clinical course in COVID-19 [3]. This might be through anti-inflammatory and immune-strengthening effects of testosterone, at least in hypogonadal individuals started on testosterone replacement therapy (TRT).

It is unclear in which ways endogenous testosterone levels are correlating with the severity of SARS-CoV2 infection. We need sound data to delineate if men who are receiving TRT have improved clinical outcomes compared to hypogonadal men not on TRT. Further evidence is needed to clarify if testosterone could be used to assist in riskstratifying patients into lower and higher risk patients and if (temporary) testosterone supplementation is of benefit to high-risk subgroups.

In summary, clinicians responsible for prescribing ADT or TRT and those caring for COVID-19 are lacking sound recommendations to determine if testosterone supplementation or even augmentation is "friend or foe." Until more data are available, we might have to conclude with the wisdom of Paracelsus: "all things are poison, and nothing is without poison; only the dose makes a thing not a poison."

Author contributions PJN: conception of the manuscript, drafting of the article, revision of the article, and final approval of the manuscript. HVG: drafting of the article, revision of the article, and final approval of the manuscript.

\section{Compliance with ethical standards}

Conflict of interest The authors declare that they have no conflict of interest.

Publisher's note Springer Nature remains neutral with regard to jurisdictional claims in published maps and institutional affiliations.

\section{References}

1. M.S. Mohamed, T.C. Moulin, H.B. Schiöth, Sex differences in COVID-19: the role of androgens in disease severity and progression. Endocrine (2020). https://doi.org/10.1007/s12020-020-02536-6

2. S. Salciccia, F. Del Giudice, M.L. Eisenberg, C.M. Mastroianni, E. De Berardinis, G.P. Ricciuti, M. Maggi, A. Sciarra, Androgen- 
deprivation therapy and SARS-Cov-2 infection: the potential double-face role of testosterone. Ther. Adv. Endocrinol. Metab. (2020). https://doi.org/10.1177/2042018820969019

3. G. Rastrelli, V. Di Stasi, F. Inglese, M. Beccaria, M. Garuti, D. Di Costanzo, F. Spreafico, G.F. Greco, G. Cervi, A. Pecoriello, A.
Magini, T. Todisco, S. Cipriani, E. Maseroli, G. Corona, A. Salonia, A. Lenzi, M. Maggi, G. De Donno, L. Vignozzi, Low testosterone levels predict clinical adverse outcomes in SARS-CoV-2 pneumonia patients. Andrology (2020). https://doi.org/10.1111/a ndr. 12821 